\title{
Gestão democrática da educação, participação política e eleição de diretores: uma análise a partir da experiência das ocupações de escolas no Rio de Janeiro
} Democratic management of education, political participation and election of
principals: analyzing the experience of school occupations in Rio de Janeiro Gestión democrática de la educación, participación política y elección de directores: una análisis desde la experiência de las ocupaciones escolares en

Rio de Janeiro

\author{
RAFAEL BASTOS COSTA DE OLIVEIRA \\ ORCID iD http://orcid.org/0000-0003-3694-0435 \\ Universidade Católica de Petrópolis - Rio de Janeiro. \\ VIRGÍNIA CECÍLIA DA ROCHA LOUZADA \\ ORCID iD: http://orcid.org/0000-0002-0529-8091. \\ Universidade do Estado do Rio de Janeiro \\ PAULO DAVID DE JESUS TOSTES DOS SANTOS \\ ORCID iD: http://orcid.org/0000-0003-1536-5718 \\ Instituto Brasileiro de Geografia e Estatística.
}

\begin{abstract}
Resumo: É nosso objetivo analisar dimensões de gestão de escola, de participação política dos estudantes e da relação com a comunidade escolar a partir das ocupações de escolas do Rio de Janeiro, em 2016. Alicerçados na experiência de dois estudantes e de um dos autores do texto, utilizamos como referencial teórico-metodológico a filosofia da práxis e do legado braudeliano. Como estratégia de pesquisa, empregamos a pesquisa-ação e entrevistas. Concluímos que esta experiência foi fundamental para a vida dos estudantes, tanto no momento do acontecimento, quanto em seus desdobramentos.
\end{abstract}

Palavras-chave: Gestão democrática da educação; Ocupações de escolas; Participação política; Experiência.

\begin{abstract}
Our purpose is to analyze the dimensions of school management, political participation of students, and the relationship with the school community from the occupations of schools in Rio de Janeiro, in 2016. Based on the experience of two students and one of the authors of the text, we used the philosophy of praxis and the Braudelian legacy as the theoretical-methodological framework. As a research strategy, we used action research and interviews. We concluded that this experience was fundamental for the students' lives, both at the time of the event and in its consequences.
\end{abstract}

Keywords: Democratic management of education. Occupation of schools. Political participation. Experience. 
Resumen: Nuestro propósito es analizar las dimensiones de la gestión escolar, la participación politica de los estudiantes y la relación con la comunidad escolar basada en las ocupaciones escolares en Río de Janeiro, en 2016. Con base en la experiencia de los estudiantes y uno de los autores del artículo. Utilizamos la filosofía de la praxis y el legado de Braudel como marco teórico-metodológico. Como estrategia de investigación, utilizamos investigaciones de acción y entrevistas. Llegamos a la conclusión de que esta experiencia fue fundamental para la vida de los estudiantes, tanto en el momento del evento como en sus consecuencias.

Palabras clave: Géstion democrática de la educación. Ocupaciones escolares. Participación política. Experiencia.

\section{INTRODUÇÃO}

Este artigo objetiva analisar os fenômenos presentes e oriundos das ocupações de escolas do Rio de Janeiro, no ano de 2016, tendo como foco a experiência da gestão da escola, quando os estudantes foram os responsáveis diretos pelas instituições, durante os três meses de ocupações. Procuramos também entender e refletir sobre a relação com o corpo administrativo durante a ocupação e após esse período. O processo de consulta para escolha de diretores de escolas ganhou maiores contornos com a promulgação, pela Assembleia Legislativa do Estado do Rio de Janeiro (ALERJ), da Lei 7.299/2016. Isto posto, as mediações em torno da respectiva lei são contempladas na análise.

Cabe destacar que concordamos com os indicativos de parte importante da literatura sobre a gestão democrática da educação, a exemplo de Paro (2016a), que entende gestão para além dos afazeres administrativos próprios dos diretores e adjuntos. Neste texto, adotamos a dimensão mais ampla de administração, que engloba a construção coletiva do Projeto Político Pedagógico da escola, a definição do currículo, o estabelecimento de relações com a comunidade escolar e, sobretudo, se pauta numa perspectiva colegiada de gestão.

$\mathrm{O}$ objeto desenhado requer tecer mediações entre particularidade e totalidade; portanto, adotamos o aporte da filosofia das práxis como referencial teórico-metodológico. $\mathrm{Na}$ dimensão da particularidade, entrevistamos (ao final de 2019) dois estudantes que foram lideranças em suas escolas na época da ocupação ${ }^{1}$. Hoje, ambos são universitários de instituições públicas. O questionário visou a apreender: a) o balanço deles das ocupações, passados três anos da experiência; b) os significados daquele momento para eles; c) se houve mudança na concepção de política e de escola, após as ocupações; d) os significados da Lei 7.299/2016 - e

1 Os nomes verdadeiros dos ex-alunos serão preservados devido ao compromisso ético firmado durante as entrevistas. Ao longo dos três anos, acompanhamos os estudantes e notamos que eles continuaram engajados com a luta política; desta forma, entender até que ponto as ocupações foram cruciais para perdurar a militância e analisar a experiência vivida nos pareceu ser um elemento provocador e merecedor de análise. 
a possível relação direta das ocupações com ela; e) se houve consulta nas escolas que eles estudavam para novos diretores, nos anos subseqüentes; f) como se deu a participação deles nesse processo.

As entrevistas apontaram categorias de conteúdo (KUENZER, 1998) que ultrapassam as fronteiras da gestão da escola, mas se relacionam dialeticamente com ela. Apresentamos esta reflexão ao final do texto. Esta é a principal base empírica do artigo.

Abarcamos também, na análise, as memórias e as experiências de um dos autores do artigo com estudantes ocupantes em escolas na zona norte da capital fluminense. A respectiva reflexão incide também sobre o exercício de entender a ocupação como acontecimento e os desdobramentos político-pedagógicos e filosóficos após este episódio. Sobre a relação com a totalidade, dedicamos um tópico para descrever as características, motivações das ocupações e a conjuntura da ocasião.

Este trabalho faz parte de um acúmulo de pesquisas anteriores. No momento das ocupações, foram feitas investigações que se caracterizaram como pesquisa-ações (TRIPP, 2005). Inúmeras categorias foram sistematizadas desde então e, no presente momento, tentamos dar conta de redimensionar o olhar sobre este objeto depois de três anos. Fundamentados no pensamento de Braudel (1981) a respeito da experiência e sua duração no tempo histórico, hoje, em um período de curta duração, notamos que o legado daqueles três meses entre março e junho de 2016 ainda perduram nas representações sociais dos discentes.

Em 2016, durante as pesquisa-ações, um dos critérios de escolha das escolas (da rede estadual de educação) foi o de abarcar regiões diferentes do estado; por conseguinte, visitamos a baixada fluminense, região serrana e metropolitana, além da cidade do Rio de Janeiro. Os estudantes entrevistados para esse trabalho eram da região serrana e da zona norte da capital fluminense ${ }^{2}$. Pensamos que é relevante abordar o que Bourdieu (1997) argumenta na relação entre sujeito e objeto, em uma pesquisa. Para o autor, dificilmente o pesquisador está à altura do objeto, pois ele não vive a experiência do próprio sujeito. Assim, a aproximação do pesquisador com a temática em questão deve ser mediada por estudos/conhecimentos aprofundados sobre o tema. O autor ainda pondera que numa entrevista o pesquisador, além de objetivar o sujeito, também é objetivado por ele, sendo a pesquisa a mediação entre ambos.

2 As escolas em questão foram: Em Petrópolis, o Colégio Estadual Dom Pedro II. Em Nova Iguaçu, Instituto de Educação Rangel Pestana. Na cidade do Rio de Janeiro, Colégio Estadual Paulo Freire e o Colégio Estadual Compositor Luiz Carlos da Vila. 
Exposta essa reflexão, pressupomos que o trato com outra perspectiva de memória, a partir de uma experiência de um dos autores e não somente por meio das entrevistas, pode ampliar o potencial analítico investigativo.

As conclusões a que chegamos apontam que a experiência vivida pelos estudantes foi fundamental para as vidas deles, tanto no momento do acontecimento, quanto no tempo de curta duração. Inúmeros aspectos, como escolha profissional, identidade, pertencimento, vontade coletiva e práxis política que eles mobilizam, são creditadas às ocupações.

\section{O QUE FORAM AS OCUPAÇÕES: BREVE ANÁLISE DE CONJUNTURA}

O movimento de ocupações de escolas, no Brasil, tem relação conjuntural com alguns episódios marcantes, a exemplo das lutas dos estudantes no Chile, em 2006. Diversas manifestações contemporâneas tiveram características regulares e comuns às ocupações de escolas, como a descentralização, crítica à forma tradicional de manifestação no campo democrático popular (via partidos de esquerda e sindicatos) e a mobilização via redes sociais. Gohn (2017) conceitua esse tipo de fenômeno como uma ação dos chamados Novos ou Novíssimos Movimentos Sociais.

Em setembro de 2015, no âmbito escolar, houve uma mudança conjuntural que eclodiu em uma série de lutas que se desenrolaram ao longo de 2016. Nesse período, em São Paulo, foram anunciadas medidas, por parte do governo do estado, que através de uma proposta denominada de reorganização escolar, indicava o fechamento de cerca de cem escolas. Além do mais, o projeto apresentado traria impacto direto na vida de um milhão de alunos que seriam transferidos das suas respectivas unidades educacionais de origem para que as escolas passassem a atender exclusivamente um ciclo educacional (ensino fundamental I, ensino fundamental II e ensino médio). Os estudantes criticavam essas medidas, pois elas se forjaram de um modo vertical, sem que os setores interessados e diretamente impactados por elas fossem consultados (CAMPOS, MEDEIROS e RIBEIRO, 2016).

Como resposta, inúmeras manifestações começaram a ganhar corpo nas ruas - entre setembro e novembro de 2015 - e se voltaram, posteriormente, para os espaços escolares. As ocupações das escolas paulistas tiveram início em 08 de novembro de 2015 e chegaram ao ápice no mês de dezembro. Mais de duzentas escolas chegaram a ser ocupadas (CAMPOS, MEDEIROS e RIBEIRO, 2016). 
O fenômeno paulista alavancou outras mobilizações no país e, em outubro de 2016, 19 estados e quase mil escolas em todo o Brasil estavam ocupadas. (GLOBO, 2016; EL PAÍS, 2016). Os estudantes se organizavam reivindicando demandas locais próprias; porém, as ocupações tinham uma mediação nacional também, a exemplo da contrariedade à Proposta de Emenda Constitucional $241^{3}$ (BRASIL, 2016b) - que tratava do congelamento dos gastos públicos, por vinte anos, em várias áreas da política social, como saúde e educação. Na ocasião houve também a luta contra a Medida Provisória 746 (BRASIL, 2016a) de reestruturação do ensino médio - que apontava para a flexibilização dos currículos escolares. Além disso, a tentativa de um golpe, que gerou o impeachment da ex-presidenta Dilma Rousseff, também era pauta de muitos debates estudantis.

Sobre os contornos locais das problemáticas da educação básica no Rio de Janeiro, o movimento de ocupações fluminense surge em uma conjuntura de crise política e econômica regional. A administração pública passava por uma forte crise, que culminou no decreto de calamidade pública por parte do governador em exercício, Francisco Dornelles (RIO DE JANEIRO, 2016).

Assim, houve atraso no pagamento dos servidores estaduais, o que fez, inclusive, com que diversas categorias entrassem em greve. Os profissionais da rede estadual de educação básica também aderiram ao movimento grevista. Diversos estudantes entrevistados na ocasião já apontavam que a greve docente foi condição sine qua non para criar um contexto de luta estudantil. As entrevistas feitas esse ano apontaram para essa mesma percepção.

\section{QUADRO CONCEITUAL: UMA REFLEXÃO SOBRE A EXPERIÊNCIA}

Um elemento incontornável dessa discussão diz respeito à experiência e a sua duração. Braudel (1981) é um dos grandes expoentes da Escola dos Annales e, nas suas reflexões inovadoras sobre o tempo, pondera que a experiência não se esgota no tempo de curta duração (ou tempo do acontecimento).

De acordo com o autor, o tempo do acontecimento é o mais caprichoso, mais enganoso das durações. Configura-se como o tempo do jornalista, que registra o flash, a notícia do agora. Para este autor, a dificuldade da historiografia de lidar com estes fatos é que os mesmos ainda não configuram uma regularidade estrutural. 
Tendo em vista ainda a contribuição braudeliana, um tempo de média duração se configura como o conjuntural, no qual determinados aspectos se manifestam com regularidade, a exemplo das variações econômicas das crises do capitalismo. $\mathrm{O}$ autor discute que mudanças vão amalgamando uma nova estrutura social e geram a longa duração. Estas mudanças são lentas, por vezes, imperceptíveis, para a geração protagonista das mudanças. À medida que se consolidam ao longo de séculos, podem ser consideradas como um tempo de longa duração.

As ocupações de escola ganharam fôlego em uma série de eventos quase que simultâneos ou ainda dentro de um espaço temporal curto (final de 2015 ao primeiro semestre de 2016). Perante esse cenário, duas reflexões vêm à tona. A primeira é que o nosso esforço de pensar a particularidade desse fenômeno (no Brasil) não descarta a mediação em relação às tendências globais de manifestações contestatórias (principalmente da juventude) de caráter um tanto quanto similar às ocupações escolares. Deste modo, percebemos que, num período um pouco superior a dez anos, há uma regularidade neste tipo de manifestações. Os escritos de Alves (2012) e Gohn (2017) ajudam a sustentar esse ponto de vista. Começamos a amadurecer o pressuposto de que talvez o início do século XXI tenha como uma das marcas, no seu tempo de média duração, manifestações de massas, na linha do que os Novos Movimentos Sociais fazem.

A segunda reflexão diz respeito ao fato de que a experiência que os sujeitos viveram nas escolas pode ter sido paradigmática para o decorrer da vida deles. Ou seja, aquela experiência não se esgota no acontecimento. Sendo assim, o ato filosófico (SAVINI, 1985), o pensar sobre a existência, a relação pedagógica com a escola e o aprender podem remeter aos dias em que eles "viraram a escola do avesso".

A proximidade investigativa com algumas lideranças das ocupações nos ajuda a formular a afirmação acima. É necessário desenvolver mais investigações que abarquem outros participantes que não eram tão protagonistas. Defendemos, contudo, que o exercício teórico aqui feito pode contribuir para análises futuras, tanto no campo da história, quanto nas áreas da sociologia e sociologia da educação. 


\section{CONSIDERAÇÕES SOBRE A PARTICIPAÇÃO POLÍTICA, A GESTÃO DEMOCRÁTICA DA EDUCAÇÃO E ASPECTOS NORMATIVOS LEGAIS}

Outro conceito chave do trabalho diz respeito à participação política. Dallari (1984) relaciona participação ao poder de decidir, assim como à incontornável convivência em coletividade. A compreensão sobre a participação política mudou muito ao longo da história da humanidade. Por exemplo, na Grécia Antiga, a política era restrita aos homens livres (ARISTÓTELES, 2010). A privação das demais pessoas não perpassava pela preocupação no espectro teórico de importantes pensadores, como o próprio Aristóteles. Ao mesmo tempo, quem realizava a política na polis grega o fazia via democracia direta. No decorrer do século XVII, a participação política ganhou novo contorno; com o advento da sociedade burguesa, a democracia representativa se consolida como uma alternativa (FONTES, s/d).

Seja através da eleição (na democracia representativa) ou da retórica (na democracia direta), Dallari (1984) defende que a omissão na possibilidade de tomada de decisão política é um gesto que em nada contribui com a sociabilidade coletiva. $\mathrm{O}$ autor é categórico ao defender a participação política como um direito fundamental moderno.

Para Bobbio (1986) a contemporaneidade dispõe de recursos, como os tecnológicos, que devem ser aperfeiçoados para garantir mais poder de participação da sociedade, essencialmente nos temas de maior apelo.

Dallari (op. cit.) argumenta também que a participação pode ser individual ou coletiva. A individual perpassa pela mera ação do sujeito. Já a coletiva, demanda um grupo social. Assim, a democracia moderna encontra o partido político como a entidade mais complexa e estruturada para pensar a relação entre política e coletividade.

Os estudantes que ocuparam as escolas tiveram a chance primorosa de promover uma democracia direta no ambiente pedagógico. Partilhamos das constatações de Nogueira (2013) e Dallari (1984) de que a modernidade se destaca mais pela prevalência da participação política, via espaços representativos, do que pelo caminho da democracia direta.

As nossas reflexões convergem com o que Gramsci (2011) elabora. Participar da vida política mobiliza a relação do sujeito com o poder, a construção de identidade, promove o exercício filosófico cotidiano, tudo isso dentro das dimensões da práxis humana. O pleito da gestão democrática na escola, materializado pelos estudantes por meio do direito à participação na seleção de diretores, contrasta com a prática então realizada no Rio de Janeiro, que consistia 
na indicação política de diretores para seus cargos. O movimento da ampliação da participação no processo decisório da gestão escolar pela comunidade escolar, no entanto, não é necessariamente novo e encontrou base legal em normativos já existentes.

No território nacional, a década de 1980 é um marco sobre a temática da gestão democrática. Foi um período marcado por muitas pautas e reivindicações nesse sentido, fruto de um cenário político após um longo período de ditadura. A Constituição Federal (BRASIL, 1988) realizou a inclusão, no Art. 205, de dispositivos específicos sobre a gestão democrática. Trata-se de um marco legal importante, pois representa a inclusão do tema no nível mais elevado do ordenamento jurídico nacional, devendo então pautar a educação brasileira e implementar a "gestão democrática do ensino público, na forma da lei" (BRASIL, 1988).

No que se refere ao âmbito específico da educação, a Lei de Diretrizes e Bases da Educação Nacional (BRASIL, 1996) é outro marco importante. Nela o princípio da gestão democrática, previsto na constituição, é mantido.

Atualmente, uma referência significativa para balizar a discussão sobre a gestão democrática gira em torno do Plano Nacional de Educação (PNE), aprovado em 2014 e com vigência até 2024 (BRASIL, 2014). A meta 19 estipula que, no ano de 2016, os entes federativos deveriam estabelecer legislações específicas sobre o tema, em seus respectivos sistemas de ensino. Destacamos que há uma amplitude do termo legislação específica, pois “a gestão democrática tanto poderá ser regulamenta por uma lei como através de um decreto, portaria, resolução ou demais mecanismos legais, marcando, dessa maneira, formas distintas de debate e participação da comunidade em cada ente federado" (AMARAL, 2019, p. 309)

Este PNE também apresenta elementos contundentes no que diz respeito à participação política e gestão democrática, pois aponta o fortalecimento de grêmios estudantis e associações de pais, dentre outras pautas (BRASIL, 2014). Nas ocupações analisadas, estes aspectos ganharam contornos veementes, o que vai ao encontro do que Dallari (1984) pondera ao afirmar que o aumento da participação política propicia o melhor entendimento da luta por direitos.

A redemocratização, a conquista de direitos no Brasil e a materialização legal destas mediações na forma de gestão democrática trazem à tona um debate presente nos dias de hoje, relacionado aos modelos de gestão da educação. Os modelos organizacionais e o modelo de gestão gerencial ganharam hegemonia e contrastam com os princípios da gestão democrática (PARO, 2016a). Muitas vezes, esse modelo de gestão gerencial se apropria de significados da gestão democrática e lhe dá novos sentidos, muitas vezes dissonantes dos sentidos originalmente propostos. 
A administração escolar busca nas escolas clássicas de administração respostas para os desafios de educar um número cada vez maior de indivíduos. Por influência do modelo gerencial, a administração escolar pode adotar posturas fiscalizadoras, centralizadoras e hierárquicas, indo de encontro aos princípios básicos da gestão democrática. Trata-se de um embate de posturas progressistas com um modus operandi tipicamente neoliberal.

O conceito de gestão democrática ficou restrito ao ensino público. Essa restrição, contudo, não pode diminuir sua relevância, pois retratou um movimento até então com baixa representatividade e que atendeu a uma demanda latente em temas como mecanismos de participação, tais como eleição de dirigentes escolares, formação de conselhos escolares, elaboração de normativos, como o regimento e o projeto pedagógico, construídos de forma coletiva, e da exclusividade do financiamento da escola pública pelo poder público, conforme o trabalho de Peroni (2013).

A gestão democrática do ensino é um elemento importante para que se realize a democratização da sociedade brasileira. São elementos constitutivos da gestão democrática a construção do projeto político-pedagógico, a eleição para diretores, a autonomia administrativa e financeira, entre outros. Trata-se de processos pedagógicos de aprendizagem da democracia, pois promovem a participação da comunidade acadêmica nas discussões e nas tomadas de decisão. A eleição para diretores não é único meio legalmente aceito para nomeação dos diretores escolares no Brasil em instituições públicas de ensino, como descreve Paro (2003). Para provimento do cargo de diretor escolar, podem-se mencionar, de forma geral, três institutos: a) o da nomeação direta; b) o concurso público e, por fim, c) a eleição pela comunidade escolar. De acordo com a literatura levantada na área e mencionada até então nesse texto, a eleição de diretores é a que melhor contempla os diversos aspectos da participação política e que potencializa a democracia, uma vez que a nomeação é pouco inclusiva politicamente e o concurso se respalda no mérito, categoria esta ampla, como aponta Amaral (2019).

A legislação que afeta o contexto legal de seleção dos diretores no município do Rio de Janeiro, por exemplo, e no estado passou por diferentes marcos legais. Com objetivo de fornecer uma visão geral desses normativos, Castro e Amaral (2019) elaboram uma tabela que resume os principais institutos do ordenamento jurídico que versam sobre o tema e auxiliam a pensar o objeto tratado no texto: 
Tabela 1 - Ordenamentos Legais e Seleção de Diretores no Estado e Município do Rio de Janeiro

\begin{tabular}{|l|c|l|}
\hline \multicolumn{1}{|c|}{ Ordenamento legal } & \multicolumn{1}{|c|}{$\begin{array}{c}\text { Ano de } \\
\text { Aprovação }\end{array}$} & \multicolumn{1}{|c|}{ Processo de seleção e diretores } \\
\hline Plano Nacional de Educação & 2014 & $\begin{array}{l}\text { Critérios técnicos de mérito, } \\
\text { desempenho e consulta à } \\
\text { comunidade escolar. }\end{array}$ \\
\hline $\begin{array}{l}\text { Constituição do estado do Rio de } \\
\text { Janeiro }\end{array}$ & 1989 & $\begin{array}{l}\text { Eleições diretas, na forma da lei, para } \\
\text { direção das instituições de ensino } \\
\text { mantidas pelo Poder Público. }\end{array}$ \\
\hline Plano Estadual de Educação & Não aprovado & \multicolumn{1}{|c|}{} \\
\hline Lei N. 7299 - Estado do RJ & 2016 & $\begin{array}{l}\text { Processos consultivos para a } \\
\text { indicação de diretores. }\end{array}$ \\
\hline $\begin{array}{l}\text { Resolução SEEDUC } \\
\text { regulamenta a Lei N.7299/16 }\end{array}$ & 2016 & $\begin{array}{l}\text { Processo consultivo para a indicação } \\
\text { de diretores. }\end{array}$ \\
\hline $\begin{array}{l}\text { Lei Orgânica município do Rio de } \\
\text { Janeiro }\end{array}$ & 1990 & $\begin{array}{l}\text { Eleição direta para direção das } \\
\text { unidades da rede municipal de } \\
\text { ensino público. }\end{array}$ \\
\hline Plano Municipal de Educação & 2018 & $\begin{array}{l}\text { Consulta à comunidade escolar por } \\
\text { meio de lei municipal para escolha de } \\
\text { diretores de unidades escolares. }\end{array}$ \\
\hline Resolução SME & 2017 & $\begin{array}{l}\text { Processo de seleção de gestores das } \\
\text { unidades escolares. }\end{array}$ \\
\hline
\end{tabular}

Fonte: Castro e Amaral (2019)

O que se percebe é uma diversidade de dispositivos legais que apresentam diferentes orientações sobre o processo de nomeação de diretores escolares. Nesse contexto, deve-se pensar sobre os estudantes mobilizados por um processo coletivo, vinculado explicitamente à inclusão destes jovens na categoria de sujeitos de direito à participação na construção de uma política pública educacional. Castro e Amaral (2019) constatam algo similar às nossas investigações, no que tange ao quanto a mobilização estudantil foi crucial no Estado do Rio de Janeiro para aprovação da lei de consulta para indicação de diretores de escola.

\section{MEMÓRIA E CATEGORIAS DE CONTEÚDO DA PESQUISA}

Nosso eixo de análise para entender as experiências vividas nas ocupações, como dito anteriormente, é o de compreender a experiência como uma categoria filosófica. Explicando melhor, "aquilo que 'nos passa', ou que nos acontece, e ao nos passar, nos forma e nos transforma” (BONDÍA, 2002, p. 26) porque muda radicalmente a nossa existência, levando em conta que nos provoca, nos tensiona, nos inquieta. 
No nosso entendimento, as experiências vividas na época em que as escolas foram ocupadas pelos estudantes são experiências que, no momento presente, impactam os sujeitos que as vivenciaram e não podem ser restritas ao acontecimento em si, uma vez que ainda provocam reflexões sobre o ocorrido. Tais experiências indicam a necessidade de se repensar a escola, suas práticas e as relações vivenciadas nos espaços escolares. São experiências que permanecem constituindo a trajetória dos estudantes, dos familiares e profissionais que atuam na área de Educação e que participaram do cotidiano das escolas ocupadas, embora as ocupações tenham terminado. Nesse sentido, concordamos com Bondía quando o autor argumenta que "a experiência é o que nos passa, o que nos acontece, o que nos toca. Não o que se passa, não o que acontece, ou o que toca." (Ibid., p. 21); em outras palavras, seus efeitos não estão restritos ao acontecimento que a gerou.

Um dos autores do artigo vivenciou, de perto, o movimento das ocupações ocorrido em 2016. Na época, intencionalmente visitou algumas escolas ocupadas no município do Rio de Janeiro, ao mesmo tempo em que convivia, em sua família, com uma jovem que participou ativamente do movimento na escola em que estava matriculada, no Ensino Médio, a quem chamaremos Marina ${ }^{4}$. Nessa seção do texto, faremos o movimento para pensar como esse acontecimento específico - o movimento de ocupação das escolas pelos/as estudantes - a partir do relato de duas experiências vividas pelo autor - ao visitar uma das escolas ocupadas e no convívio com a jovem em questão - constituiu um momento de grande aprendizagem e reflexão para ele, hoje professor universitário (e, durante muitos anos, professor da escola básica). O esforço de rememorar os fatos parte do princípio de que

A memória, ao mesmo tempo que nos modela, é também por nós modelada. Isso resume perfeitamente a dialética da memória e da identidade que se conjugam, se nutrem mutuamente, se apóiam uma na outra para produzir uma trajetória de vida, uma história, um mito, uma narrativa (CANDAU, 2014, p. 16).

A primeira situação aconteceu em uma visita à Unidade Tijuca II do Colégio Pedro II, localizada no bairro da Tijuca. A visita em questão foi acompanhada pela filha desse professor, na ocasião com oito anos, que entusiasmada com a possibilidade de conhecer uma escola ocupada pelos estudantes, levou consigo material para anotar tudo o que considerasse importante de ser visto no local. Ou seja, o primeiro aspecto que merece ser destacado é o fato de que a simples 
vivência de conhecer esse espaço reconfigurado gerou uma mobilização na criança, que sentiu a necessidade de aproveitar ao máximo aquela experiência, utilizando o registro como possibilidade de memória.

Ao final da visita, um dos jovens responsáveis pelo movimento naquela escola dirigiu-se ao professor e perguntou a idade da criança. Quando soube que a menina tinha oito anos, se limitou a fazer o seguinte comentário: "Coitada!", fato que lhe aguçou a curiosidade. Diante do comentário, coube perguntar o porquê de ter dito aquilo. A justificativa foi a seguinte: "porque ela tem mais dez anos de escola pela frente". No mínimo, parecia-lhe paradoxal um comentário dessa natureza feito pelo jovem, levando em conta que ele próprio estava dormindo na escola (inclusive naquele final de semana, com uma das fases do Exame Nacional do Ensino Médio - ENEM - em curso), abrindo mão do conforto da sua casa, justamente para, entre outras possibilidades, ressignificar aquele espaço e as suas práticas.

Aquele comentário causou um profundo descontentamento no professor. O que se limitou a dizer, na ocasião, foi o seguinte: "não é possível que algo diferente não possa ser feito em tanto tempo!”. Tal comentário o pegou de surpresa, foi necessário um tempo para pensar a respeito. Até os dias atuais, aquele estudante continua refletindo sobre esse breve diálogo ocorrido no final de 2016 - breve, na sua composição; contudo, profundo na possibilidade de análise para o próprio movimento e na denúncia de uma escola que não dá conta dos anseios e necessidade da juventude que a frequenta.

Pouco tempo depois dessa visita, o movimento de ocupações se encerrou. Marina, a jovem que convivia com o professor, frequentava a Escola Técnica Estadual Adolpho Bloch e ficou profundamente cabisbaixa, triste com o que significava o retorno da rotina escolar antes daquele cenário. Questionada sobre o motivo de tamanha tristeza, se limitou a dizer: "simplesmente não conseguirei voltar à escola, não depois do que vivemos no período das ocupações... como poderei estar lá, vivendo do mesmo jeito de antes, fingindo que nada aconteceu?”

A jovem evidencia o que Bondía defende como possibilidade de atravessamento no sentido da experiência. Para o autor, a experiência "ao nos passar, nos forma e nos transforma." (Ibid., p. 26). Como se adequar a uma escola muitas vezes desconectada com as suas necessidades depois de ter vivido o protagonismo possibilitado pela ocupação do espaço escolar? Nesse sentido, a experiência escolar não deveria se restringir a “(...) 'raciocinar' ou 'calcular' ou 'argumentar', como nos tem sido ensinado algumas vezes, mas (...), sobretudo, dar sentido ao que somos e ao que nos acontece”. (Ibid., p. 21). A escola, após aquele acontecimento específico, não poderia ser a mesma, porque os sujeitos que habitavam a escola não eram os mesmos. A possibilidade de se pensar o retorno 
àquela realidade lhe causava um profundo sofrimento, uma vez que a memória recente de práticas escolares engessadas não lhe possibilitava enxergar, naquele momento, que aquele retorno, por mais doloroso que fosse, poderia ser o anúncio de outras possibilidades de acordos mais democráticos e participativos.

Da mesma forma, o professor em questão, mesmo com tantos anos atuando no magistério, não podia dizer que aquele acontecimento - o movimento de ocupação das escolas - havia simplesmente passado pela sua existência. O movimento em questão, no seu ponto de vista, evidenciava algo que já havia percebido ao longo de sua trajetória profissional: a necessidade premente de se repensar a escola (e as suas práticas) coletivamente, a partir do protagonismo dos estudantes.

Seguindo a linha de raciocínio - a possibilidade de a experiência de ocupação da escola também ter afetado outros estudantes que viveram esse processo - consideramos relevante entrevistar outros jovens que participaram ativamente do movimento. Entrevistamos dois alunos (de gênero e municípios distintos), lideranças em suas escolas na época das ocupações, com os quais nos mantivemos em contato. Para manter o anonimato dos entrevistados, nomes fictícios foram utilizados. Nomeamos o primeiro jovem como Osvaldo, na época em questão, aluno da unidade de Petrópolis do Colégio Dom Pedro II. Nomeamos a segunda jovem como Laís, estudante do Colégio Estadual Luiz Carlos da Vila, localizado no bairro de Manguinhos, na cidade do Rio de Janeiro. Começamos a pensar mais a fundo as entrevistas ${ }^{5}$ pela fala de Laís:

É... eu gosto muito desse tema, e acho que as ocupações em 2016 foram um "respirar" para nossa política, pra nossa esperança, principalmente para quem tá envolvido com a educação. Pra quem tá pensando políticas públicas, tanto pessoal quanto coletivo. (...) Acredito que a gente precisa organizar essa galera. Botar essa galera pra pensar (...). Os alunos secundaristas têm muita energia, tem muita força de vontade, tem muita determinação. Eu lembro que no mesmo dia que a gente fez a assembleia, no mesmo dia a gente ocupou e ficou por dois meses. (...) Foi uma experiência de muito aprendizado, de construção de laços que nunca vão ser quebrados, porque eu acredito que é na luta que a gente constrói mesmo uma sociedade mais justa com muito aprendizado. (...) Eu acho que é um tema que precisa ser estudado, pra gente tá passando para as pessoas, e que precisa ser estimulado. (LAÍS)

A fala da estudante entrevistada apresenta diversas nuances; sobre a experiência e a sua duração, revela, inclusive, que aqueles dias influenciaram a sua escolha profissional. Atualmente ela cursa Pedagogia em uma universidade

Não realizamos adequação das transcrições à norma culta da Língua Portuguesa, como forma de mantermos o mais fielmente possível o registro das falas dos entrevistados. 
federal do Rio de Janeiro e, durante a entrevista, citou Paulo Freire, a certa altura, destacando o quão é importante ser sujeito ativo na escola, aspecto esse que impulsiona a criticidade, um olhar pra si e pro seu lugar no mundo.

Osvaldo também traz um ponto de vista altamente interessante sobre a respectiva experiência. Além da dimensão subjetiva, ele cita ganhos materiais na escola proporcionados pela luta estudantil, como a aquisição de materiais. Trotsky (2009) chama a atenção exatamente para a importância da conquista de ganhos materiais em qualquer luta classista como um elemento chave para construção de uma consciência dos processos de luta e de organização coletiva. Vejamos como esta perspectiva se materializa nos próprios termos do estudante:

Bom, pra mim, especificamente, foi uma experiência muito grande, porque você
começa a ver a escola numa maneira totalmente diferente do que você tem o
costume de ver. (...) Tinha uma galera ali que cumpria o pouco da política ali da
escola e que teve essa atitude; mas alguns anos antes eu não era esse estudante
tão assíduo e não me importava tanto com as coisas. Então, assim, a gente
acabou começando a ver de uma maneira diferente, porque você ficar dormindo
no colégio, limpando o colégio, você tá confiando no colégio, você tá morando
no colégio, né? Então, você começa a tratar o espaço que você tá morando, tá
convivendo, como se fosse a casa, né? (...) Então, a gente chega num processo,
quero deixar isso ressaltado, porque a gente ocupou em 2016 , sendo estudantes, e
agora em 2019 , se formando. Estudantes que pegaram essa ocupação do começo.
Então, querendo ou não, que pensam como uma cultura da escola, que rompe
muitas barreiras. Hoje, por exemplo, um dos laboratórios que a gente pedia há
tempos vai ser inaugurado esse ano. Então, assim, as pessoas estão vendo ainda
as coisas acontecerem; obviamente tem aquela parcela que não pegou nada, não
viu nada... mas quem tá lá, os professores, os diretores, os inspetores, todo
mundo lembra das coisas. Ainda mais porque nessa ocupação a gente para de ver
o professor lá, daquele lado, sentado na mesa dele, como um ser intocável, e a
gente começa a ter uma relação mais de amizade com eles. (OSVALDO)

Entendemos que uma categoria importante oriunda das pesquisas feitas é a vontade coletiva. Gramsci (2011) pondera que, na modernidade, a vontade coletiva deve possuir uma dimensão jacobina, promovedora de uma reforma intelectual, moral, além de mudanças no padrão econômico de vida. Para o autor, a vontade política corresponde a uma atividade política, prática, ou uma práxis política; prática esta que é feita pelo sujeito, podendo desenvolver no mesmo uma formação de consciência de classe (coletiva). Este processo caracteriza a passagem de uma consciência meramente individual de mundo para uma consciência classista.

Laís assegura que as ocupações "despertaram uma potência" nela e em outros discentes. A passagem a seguir, do estudante Osvaldo, retrata essa dimensão da ocupação: 
O próprio movimento que se inseriu ali, naquele espaço: movimentos tanto estudantis, tanto também dos profissionais de educação, mas mais dos professores mesmo. Mudou muito a cabeça da galera em entender a importância de lutar, a importância de poder construir alguma coisa na escola. (OSVALDO)

A jovem articula uma perspectiva de práxis filosófica, de luta coletiva, tendo o processo educativo como mediação para possibilidades transformadoras:

Hoje eu percebo que essa potência foi despertada na ocupação. A potência de questionar, de se colocar à disposição da luta, e principalmente, de buscar uma teoria e entender o que tá por detrás de todo esse sistema, que é um sistema historicamente eurocêntrico, uma perspectiva burguesa também. (LAIS)

\section{Sobre a relação entre os alunos, professores e direção da escola} foi possível notar uma tríade relevante. Primeiramente, os próprios estudantes entrevistados relatam que o movimento grevista docente ajudou a impulsionar as ocupações estudantis. Por outra via, o subsídio político-pedagógico de parte da comunidade docente também proporcionou uma sociabilidade favorável aos discentes, assim como proporcionou apoio logístico em alguns casos. Nesse sentido, Osvaldo destaca:

A primeira coisa que a gente pode falar é que a nossa relação com a direção no momento da ocupação foi muito boa, apesar de a gente conhecer colégios que não tiveram esse tipo de relação com a direção. (...) Diferentemente da maioria das escolas, com a abertura muito grande em direção ao Estado, que a todo momento estava dialogando com a gente e tentando fazer a mediação entre o que o estudante queria e o que o Estado poderia proporcionar. A gente conseguiu esse caráter muito importante e é uma coisa que pesou muito pra gente: a ajuda dos professores. Afinal, seria muito difícil manter a estrutura toda da ocupação sem a ajuda dos professores. (OSVALDO)

Destacamos que esses trechos tratados, a partir das entrevistas, convergem com pilares da concepção de gestão democrática abordados por Paro (2016b). Laís segue a mesma perspectiva:

Foi um momento onde os professores estavam pedindo reajuste salarial, estavam pedindo por benefícios. E essa greve dos professores foi a greve mais longa. Foi de quatro meses, porque os professores entraram em greve e depois de um mês teve a ocupação, e depois as ocupações aumentaram. Então, isso fez com que a pressão pelo reajuste e pelas causas dos professores aumentasse; fez com que a gente conseguisse derrubar o SAERJ, fez com que a gente conseguisse eleição pra direção. Então, a gente percebe que teve muita conquista. Mas por conta dessa mobilização de alunos independentes, alunos que não tinham contanto algum com o que é a política, com esse conceito, com esse papel político na sociedade. (LAÍS) 
Notamos que as ocupações tiveram um caráter enaltecedor de uma experiência que trouxe à tona a sensação do pertencimento à escola. As falas de Laís, de Osvaldo e da Marina induzem-nos à mesma constatação. No caso de Laís, este pertencimento veio associado à construção da identidade; ela ressalta que a influenciou na aceitação de sua negritude, na sua compreensão sobre ser mulher e moradora de uma determinada região da cidade. Vejamos:

As ocupações foram um espaço de resistência, de troca, de saberes. De união, de unidade. Eu diria que após os três anos eu entendo palavras e conceitos como "pertencimento" como um marco. Eu não me encontrava como uma moradora de Manguinhos, como uma pessoa que tem capacidade de construir algo ali (em Manguinhos). Eu só ia pra casa, dormia, e não tinha um vínculo com aquele meu espaço, com aquela minha terra, com as pessoas... eu não tinha nenhuma relação de pertencimento. E isso foi o que a ocupação me trouxe. Eu entendo, agora, Manguinhos como um espaço de construção de saberes, de cultura, de arte, de produção mesmo. Não apenas como um espaço de violência, como muitas das vezes a gente vê a favela, né. E após a ocupação, eu entendo que isso foi o resultado: a construção de pertencimento, de uma família; e que por mais que as pessoas tenham tido diversos caminhos, hoje ainda assim a gente se encontra, e a gente vê no olhar do outro que ainda tem um vínculo, né, daquilo tudo que a gente passou juntos, e tal. Então, foi uma experiência que me trouxe um crescimento, um amadurecimento. (...) Foi o que me fez escolher a pedagogia como um curso, como graduação. Trouxe muitos questionamentos internos, em relação ao cabelo, por exemplo: trouxe o questionamento da minha negritude, a apropriação de toda uma história, porque dali eu fui começando a entender o que era o feminismo, o que era o feminismo negro, os conceitos de fascismo, do que é a falta dessa olhada, dessa história negra nos livros didáticos. Então, esses questionamentos todos me resultaram numa pessoa mais empoderada. Então, também eu acredito que o empoderamento nesses três anos depois da ocupação foi fundamental, sim. (LAÍS)

\section{CONSIDERAÇÕES FINAIS}

As conclusões às quais chegamos apontam que a experiência vivida pelos estudantes foi fundamental para as vidas deles, tanto no momento do acontecimento, quanto no tempo de curta duração. Inúmeros aspectos como identidade, pertencimento, vontade coletiva e práxis política que eles mobilizam são creditadas às ocupações.

As falas de Marina, Laís e Osvaldo indicaram como foi difícil voltar a conceber a escola da mesma forma, nos mesmos moldes de gestão antes da ocupação, especialmente agora após a experiência de ser sujeito ativo da gestão escolar. 
Laís ponderou, na entrevista, que muitos grêmios estudantis foram criados; porém, muitos estudantes que não participaram do movimento tenderam a cooptação por parte da influência, tanto da direção escolar ou de gestores de escala maiores da Secretaria de Estado de Educação. Ela entende que há uma diferença de sociabilidade e trato com a lei de consulta de escolha de diretores entre estudantes que ocuparam e os que não ocuparam escolas. Esse é um pressuposto que merece aprofundamento investigativo futuro.

No caso do Rio de Janeiro, as entrevistas realizadas, as demais pesquisas feitas e as referências teóricas levantadas apontam que o aprimoramento da gestão democrática tem como um ponto de corte fundamental as ocupações de escolas. Ao que tudo indica, a vontade coletiva mobilizada pelos discentes captou essa mediação da práxis de luta.

\section{REFERÊNCIAS}

ALVES, Giovanni. Ocupar Wall Street... e depois? In: HARVEY, David (Et al.) Ocuppy: Movimentos de Protestos que tomaram as ruas. São Paulo: Boitempo: Carta Maior. 2012.

AMARAL, Daniela Patti do. Seleção de diretores de escolas públicas. Educação (Porto Alegre), v. 42, n. 2, p. 308-317, maio-ago. 2019.

ARISTÓTELES. A Política. 1 ed., São Paulo: Folha de S. Paulo, 2010.

BOBBIO, Norberto. O futuro da democracia (uma defesa das regras do jogo). Rio de Janeiro, Paz e Terra, 1986.

BONDÍA, Jorge Larrosa. Notas sobre a experiência e o saber da experiência. Revista Brasileira de Educação, Jan/Fev/Mar/Abr 2002, № 19.

BOURDIEU, Pierre. (Coord.) A Miséria do mundo. Petrópolis, RJ: Vozes, 1997.

BRASIL. Constituição da República Federativa do Brasil. Brasília 5 out. 1988. Diário Oficial da União. Brasília, 1988. Disponível em: <Disponível em: http://www.planalto.gov.br/ccivil_03/constituicao/constituicaocompilado.htm >. Acesso em: 03 nov. 2019.

BRASIL. Lei $\mathbf{n}^{\mathbf{0}} \mathbf{9 . 3 9 4}$, de 20 de dezembro de 1996. Estabelece as diretrizes e bases da educação nacional. 
BRASIL. Lei $\mathbf{n}^{\mathbf{0}}$ 13.005, de 25 de junho de 2014. Aprova o Plano Nacional de Educação - PNE e dá outras providências. Diário Oficial da União, Brasília, DF, 25 jun. 2014. Disponível em: https://www2.camara.leg.br/legin/fed/lei/2014/ lei-13005-25-junho-2014-778970-publicacaooriginal-144468-pl.html. Acesso em: 30 mar. 2020.

BRASIL. Medida Provisória $\mathbf{n}^{\mathbf{0}}$ 746, de 22 de setembro de 2016. Institui a Política de Fomento à Implementação de Escolas de Ensino Médio em Tempo Integral, altera a Lei no 9.394, de 20 de dezembro de 1996, que estabelece as diretrizes e bases da educação nacional, e a Lei no 11.494 de 20 de junho 2007, que regulamenta o Fundo de Manutenção e Desenvolvimento da Educação Básica e de Valorização dos Profissionais da Educação, e dá outras providências. Brasília, 2016a. Disponível em: < https://legis.senado.leg.br/sdleg-getter/documento?dm $=4708607 \&$ disposition $=$ inline $>$. Acesso em: 28 out. 2019.

BRASIL. Emenda Constitucional $\mathbf{n}^{\mathbf{0}} \mathbf{9 5}$, de 15 de dezembro de 2016. Altera o Ato das Disposições Constitucionais Transitórias, para instituir o Novo Regime Fiscal, e dá outras providências. Brasilia, 2016b.

BRAUDEL, Fernand. História e Ciências Sociais. $3^{a}$ Ed. Lisboa: Editorial Presença, 1981.

BOURDIEU, Pierre. (Coord.) A Miséria do mundo. Petrópolis, RJ: Vozes, 1997.

CANDAU, Joël. Memória e identidade. Tradução Maria Letícia Ferreira. 2. Reimpressão. São Paulo: Contexto, 2014.

CASTRO, M.; AMARAL, D. P. Seleção de diretores de escola como demanda do movimento estudantil: a agenda dissonante da política no Rio de Janeiro. Jornal de Políticas Educacionais. V. 13, n. 2. Janeiro de 2019.

CAMPOS, Antonia; MEDEIROS, Jonas; RIBEIRO, Marcio (2016). Escolas de Luta. Coleção Baderna. São Paulo, Veneta.

DALLARI, Dalmo. O que é Participação Política. São Paulo: Abril cultural: brasiliense, 1984. 
EL PAIS. (2016) PEC 241: Com quase 1.000 escolas ocupadas no país, ato de estudantes chega a SP. Disponível em: <http://brasil.elpais.com/ brasil/2016/10/24/politica/1477327658_698523.html>. Acesso em: 20 dez. 2016.

FONTES, Virgínia. Sociedade Civil: Dicionário da Educação Profissional em Saúde (Verbetes) Disponível em: <http://www.epsjv.fiocruz.br/dicionario/ verbetes/socciv.html>. Acesso em: 30 mar. 2017. (s/d)

GLOBO. Ocupação de escolas e universidades chega a 19 estados. Bom dia Brasil: Edição do dia 26/10/2016. Disponível em: < http://g1.globo.com/ bom-dia-brasil/noticia/2016/10/ocupacao-de-escolas-e-universidades-chega19-estados.html>. Acesso em: 20 dez. 2016.

GOHN, Maria da Glória. Manifestações e protestos no Brasil: correntes e contracorrentes na atualidade. São Paulo: Cortez, 2017.

GRAMSCI, Antônio. Cadernos do Cárcere, v. 3. Maquiavel - Notas sobre o Estado e Política. $4^{a}$ ed. Ri ode Janeiro. Civilização Brasileira. 2011.

HARVEY, David (et. al.) Ocuppy: Movimentos de Protestos que tomaram as ruas. São Paulo: Boitempo: Carta Maior. 2012.

IBGE, Diretoria de Pesquisas, Coordenação de Trabalho e Rendimento, Pesquisa Nacional por Amostra de Domicílios 2007/2015. Disponível em: < https:// brasilemsintese.ibge.gov.br/educacao/taxa-de-escolarizacao-das-pessoas-de-6-a14-anos.html >. Acesso em: 03 nov. 2019.

KUENZER, Acácia Zeneida. Desafios Teórico-metodológicos da relação trabalho-educação e o papel social da escola. In: FRIGOTTO, Gaudêncio (org.). Educação e crise do trabalho: perspectivas de final de século. Petrópolis: Vozes, 1998.

NOGUEIRA, Marco Aurélio. As ruas e a democracia: ensaios sobre o Brasil contemporâneo. Brasília: Fundação Astrogildo Pereira (FAP); Rio de Janeiro: contraponto, 2013.

PARO, Vitor Henrique. Diretor Escolar: educador ou gerente? São Paulo: Cortez, 2016a. 
PARO, Vitor Henrique. Gestão democrática da educação pública. $4^{a}$ ed. São Paulo: Cortez, 2016b.

PARO, Vitor Henrique. Crítica da estrutura da escola. São Paulo: Cortez, 2011.

PARO, Vitor Henrique. Eleição de diretores: a escola pública experimenta a democracia. São Paulo: Xamã, 2003.

PERONI, Vera M. V. A privatização do público: implicações para a democratização da educação. In: PERONI, V. M. V. (Org.). Redefinições das fronteiras entre o público e o privado: implicações para a democratização da educação. Brasília: Líber Livro, 2013. p. 9-32

RIO DE JANEIRO (Estado). Lei ${ }^{\circ}$ 7299, de 03/06/2016. Dispõe sobre o estabelecimento de processos consultivos para a indicação de diretores e diretores adjuntos das instituições de ensino integrantes da rede da Secretaria de Estado de Educação e da Fundação de Apoio à Escola Técnica - FAETEC. Rio de Janeiro, 2016. Disponível em: < http://alerjln1.alerj.rj.gov.br/CONTLEI.NSF/ c8aa0900025feef6032564ec0060dfff/faa481bd18c5c3e583257fcb0061ea02?Ope nDocument>. Acesso em: 29 out. 2019.

RIO DE JANEIRO (Município). Lei $\mathbf{n}^{\circ}$ 6362, de 28/05/2018. Aprova o Plano Municipal de Educação - PME e dá outras providências. Rio de Janeiro, RJ, 2018. Disponível em: < https://leismunicipais.com.br/a1/rj/r/rio-de-janeiro/leiordinaria/2018/636/6362/lei-ordinaria-n-6362-2018-aprova-o-plano-municipalde-educacao-pme-e-da-outras-providencias $>$. Acesso em: 27 out. 2019.

RIO DE JANEIRO. Decreto 45.692, de 17/06/2016. Decreta estado de calamidade pública, no âmbito da administração financeira do estado do Rio de Janeiro, e dá outras providências. Rio de Janeiro, 2016. Disponível em: < http:// www.age.fazenda.rj.gov.br/age/faces/oracle/webcenter/portalapp/pages/ navigation-renderer.jspx?_afrLoop $=28039325917226567 \&$ datasource $=$ UCMSe rver\%23dDocName\%3AWCC310494\&_adf.ctrl-state=1cx4dapyh3_9>. Acesso em: 28 out. 2019.

SAVIANI, Dermeval. Educação do senso comum à consciência filosófica. São Paulo: Ed. Autores Associados, 1985. 
TRIPP, David. Pesquisa-ação: uma introdução metodológica. Educação e Pesquisa, São Paulo, v. 31, n. 3, p. 443-466, set./dez. 2005. Disponível em: <http://w.scielo.br/pdf/ep/v31n3/a09v31n3>. Acesso em: 3 nov. 2019.

TROTSKY, Leon. Escritos sobre sindicato. $2^{a}$ Ed. Brasília: Nova Palavra. 2009.

\section{Rafael Bastos Costa de Oliveira}

Doutor em Políticas Públicas e Formação Humana, pela UERJ. Docente da Faculdade de Educação - UERJ, Departamento de Estudos de Políticas Públicas, Avaliação e Gestão da Educação. Docente também do Programa de Pós-Graduação em Educação - Universidade Católica de Petrópolis. E-mail: rafaelbastosoliveira@yahoo.com.br

\section{Virgínia Cecília da Rocha Louzada}

Doutora em Educação (UFF), Professora Adjunta da Faculdade de Educação da Universidade do Estado do Rio de Janeiro (UERJ) e do Programa de PósGraduação em Educação (ProPEd), na linha de pesquisa "Infância, Juventude e Educação", Coordenadora do Grupo de Estudos e Pesquisas em Políticas, Avaliação e Infâncias(GEPPAI).). E-mail: virginia.louzada@uerj.br

\section{Paulo David de Jesus Tostes dos Santos}

Mestre em Administração de Empresas (PUC/RJ). Analista de Planejamento e Gestão do Instituto Brasileiro de Geografia e Estatística (IBGE). Doutorando do Programa de Pós-Graduação da Universidade Católica de Petrópolis (UCP). E-mail: paulo.tostes@gmail.com 